\title{
“Toda la creencia está allá”. Linderos interculturales, espacios y derechos en migrantes agrícolas temporales de la península de Yucatán en Quebec
}

\author{
"All Belief is beyond". Intercultural Boundaries, \\ Spaces and Rights in Temporal Agricultural Migrants \\ from the Yucatán Peninsula in Quebec
}

\author{
Adriana Leona Rosales Mendoza \\ Universidad Pedagógica Nacional
}

\begin{abstract}
ReSUMEN: En este artículo se presentan resultados de una investigación efectuada con trabajadores agrícolas temporales en Quebec, Canadá, y en las cabeceras municipales de Maní, Mama y Dzidzantún, Yucatán, así como El Ramonal, Quintana Roo. En él se da cuenta de algunas experiencias de migrantes de la península de Yucatán que participaron en el Programa de Trabajadores Agrícolas Temporales en Quebec, Canadá (PTAT), durante 2012. Se realiza una descripción de la interacción entre algunos aspectos de las culturas de origen y de destino, poniendo énfasis en las estrategias que desarrollan los migrantes en el proceso de migración, trascendiendo el modelo dicotómico -de los estudios sobre la migración- enfocado en la sociedad receptora y las afectaciones subsecuentes en la sociedad autóctona. Este estudio exploratorio incluye técnicas de recolección de datos cuantitativas, y cualitativas, como observación etnográfica y entrevistas semiestructuradas, realizadas en México y Canadá.
\end{abstract}

Palabras clave: trabajadores agrícolas, migración, intercultural, derechos humanos, accommodements raisonnables.

AвsтRACT: This article reports the results of a research project undertaken with temporal agricultural workers in Quebec, Canada, and in the municipalities of Maní, Mama and Dzidzantún in the state of Yucatán, and El Ramonal in the state of Quintana Roo. In this article, I analyze some of the experiences of migrants from the Yucatan peninsula who participated in the Program for Agricultural Temporal Workers in Quebec, Canada (PTAT) during 2012. I undertake an interactional analysis between the cultures of origin and of destination, with an emphasis on the strategies that workers use for their migration process. This is done with the intent of transcending the dichotomous model that focuses on the receptive society and the subsequent affectations of the autochthonous society. This exploratory study included quantitative and qualitative techniques, like ethnographic observation and semistructured interviews, both in Canada and Mexico.

KEYwoRDs: Agricultural workers, immigration, intercultural, human rights, reasonable accommodations.

RECEPCIÓN: 31 de agosto de 2015.

ACEPTACIÓN: 26 de octubre de 2015.

DOI: 10.19130/iifl.ecm.2016.48.754 
En la Atenas de hoy día, los transportes colectivos se llaman metaphorai. Para ir al trabajo o regresar se toma una "metáfora", un autobús o un tren. Los relatos podrían llevar también ese bello nombre: cada día, atraviesan y organizan lugares; los seleccionan y los reúnen al mismo tiempo; hacen con ellos frases e itinerarios. Son recorridos de espacios (...) de aquí (París) se va allá (Montargis); este lugar (una pieza) incluye otra (un sueño o un recuerdo); etcétera.

Michel de Certau

\section{Introducción}

La migración internacional por cuestiones laborales es un fenómeno social cada vez más frecuente; muchas personas se ven en la necesidad de emplearse en lugares distantes de sus hogares y comunidades, y en esas circunstancias, algunos de sus derechos humanos son vulnerados. En Quebec, se ha hecho evidente que las condiciones de vida de muchos inmigrantes no son adecuadas, aun a pesar de las discusiones teóricas sobre la relevancia de la interculturalidad y de la lucha de ciertos movimientos políticos por hacer valer el respeto a la diversidad cultural. Las desigualdades en el ejercicio de ciertos derechos para nacionales y extranjeros han sido visibles, de manera particular, a raíz de los debates sobre los denominados accommodements raisonnables (integración o adaptación razonable de los inmigrantes a la sociedad quebequense), a través de los cuales se intenta llegar a acuerdos sobre qué prácticas culturales son adecuadas y cuáles otras no lo son. Las tensiones se encuentran, sobre todo, en las expresiones de religiosidad de los inmigrantes, entre ellos, los seguidores del Islam. En este contexto, los trabajadores agrícolas temporales connacionales, algunos de ellos de la península de Yucatán, ni siquiera son parte del debate sobre los accommodements raisonnables pues no "incumplen", por decirlo de alguna manera, los valores y costumbres de la mayoría quebequense, como es el caso de las mujeres musulmanas que pugnan por la utilización del hijab en sus lugares de trabajo. Los inmigrantes agrícolas temporales no cuestionan las normas sociales -o lo hacen poco- pues su meta consiste en trabajar y ahorrar lo más que se pueda para retornar a sus comunidades al finalizar su contrato; sin embargo, están igualmente expuestos a padecer discriminación, abusos de sus empleadores y vulneración de sus derechos humanos. Por lo que el hecho de que no sean parte de los accommodements raisonnables, más que colocarlos en una situación favorable, los excluye.

En este artículo se presentan resultados de una investigación realizada en SaintRémi, ${ }^{1}$ Quebec, Canadá, así como en tres municipios de Yucatán y uno de Quintana

${ }^{1}$ La villa de Saint-Rémi, Quebec, se ubica al sur del río Saint-Laurent y de la isla de Montreal; pertenece al municipio de Les Jardins de Napierville en la región administrativa de Montérégi, y posee una población de 7,265 personas, principalmente francófonos (Gouvernement du Canada: Statistics Canada, 2012: 1). Es una ciudad a la que acuden los trabajadores agrícolas temporales a realizar sus compras y a actividades de esparcimiento, ya que está próxima a tres de las granjas en las que labo- 
Roo, México; en ella se exploraron percepciones en torno a la experiencia de la migración de trabajadores agrícolas temporales peninsulares. Se destacan algunas condiciones laborales y ciertas problemáticas vinculadas con el ejercicio de sus derechos. Además, se describen algunas experiencias subjetivas, en las que se expresa el sentido de identidad que pervive más allá de las fronteras.

En el análisis realizado con base en relatos de los entrevistados se puede percibir que la concepción sobre el trabajo agrícola se configura a partir de la experiencia de vivir la milpa yucateca como "espacio practicado"; no así el campo agrícola quebequense, el cual se convierte sólo en un lugar de trabajo, es decir, la cultura, sus valores, creencias, mitos, rituales, etcétera, se expresan de manera distinta en un sitio y en otro; por ello, "toda la creencia está allá" (en la península de Yucatán) y no es factible que los chaques se encuentren en el campo canadiense. Por otro lado, la experiencia de migrar guarda relación con la construcción sociocultural de la diferencia sexual: el género, pues, a menudo, hombres y mujeres mayas peninsulares perciben que hay espacios y papeles predominantemente masculinos, como es trabajar en campos agrícolas en el extranjero, al igual que existen actividades sólo femeninas, como permanecer en el hogar para la atención de la familia. Antes de analizar los espacios mencionados describiré de manera breve en qué consiste el Programa Trabajadores Agrícolas Temporales (PTAT), así como el contexto social de la interculturalidad y los accommodements raisonnables en Quebec, y su relación con la migración.

\section{El Programa Trabajadores Agrícolas Temporales en Canadá y Quebec}

Entre las aproximaciones teóricas para el estudio de las migraciones ha prevalecido el modelo dicotómico ortodoxo enfocado en la sociedad receptora y las afectaciones subsecuentes en la sociedad autóctona. Varios autores, entre ellos, Rouse, Kearney y Nagengast, y Shiler (citados por Becerril, 2011: 21), propusieron una perspectiva teórica de la migración con base en el análisis de las comunidades transnacionales, en donde se destaca que los migrantes no se desligan de sus culturas de origen, sino que sus experiencias los acompañan cotidianamente en el país al que van a trabajar. En ese sentido, se toma aquí la propuesta de Ofelia Becerril, de realizar un análisis de la interacción entre las culturas de origen y de destino, enfatizando "la agencia humana, la subjetividad, y las estrategias puestas en juego por los migrantes" en el proceso que implica ir de un lugar a otro (ibid., 21-22).

raban los mexicanos: "Isabelle", "L'Assomption" y "Les Fermes du Soleil". Como no se me permitió entrar a sus lugares de trabajo, durante los fines de semana busqué a los trabajadores en diferentes sitios de la villa de Saint-Rémi, a saber, el centro comercial al que llegaban a hacer sus compras, el restaurante mexicano, la casa de envíos de dinero existente en la comunidad, el centro de apoyo a inmigrantes Travailleurs et Travailleuses Unis de Lalimentation et du Commerce (TUAC), el lugar de reunión que les proporciona la iglesia católica, el café Internet y el bar. Ahí encontré y re-entrevisté a tres de los ocho yucatecos y quintanarroenses con quienes me había reunido en México. De modo adicional, platiqué con migrantes de Veracruz, Colima, Hidalgo y el Estado de México. 
El análisis del modelo de migración transnacional ha generado nuevas teorizaciones sobre los efectos de los movimientos globales en las sociedades; en este modelo, los migrantes son considerados como participantes activos en constante flujo (Re, 2009: 122). De acuerdo con Alicia Re, antes de la existencia del transnacionalismo como modelo de análisis, existían tres metanarrativas relacionadas con la migración: modernización, dependencia y la teoría del sistema mundial. Desde la modernización se asumía que la migración a centros urbanos era necesaria para el desarrollo y la prosperidad económica; la teoría del sistema mundial se considera como un modelo de post-dependencia que concibe al mundo como una división global del trabajo en el que la mano de obra migrante y el flujo de excedentes desde la periferia hacia el núcleo, así como la inversión de capital, fluyen en dirección opuesta: El postmodernismo representó un cambio paradigmático en estas concepciones, pues comenzaron a explorarse las complejidades de lo local y las dinámicas y procesos dentro de las relaciones dialécticas locales/ globales generadas a través de la migración, más allá de lo macro y lo global (Re, op. cit., 133).

De esta manera, la antropología de la migración ha sido testigo del surgimiento del transnacionalismo y de nuevos modelos de análisis que permitan comprender las prácticas migratorias contemporáneas (Basch et al., 1994, citado por Re, ibid., 134). Los movimientos translocales (migración rural-urbana) desdibujan fronteras nacionales y locales, y las migraciones provocan procesos de diversidad cultural, que responden a diferentes configuraciones políticas, sociales, económicas e ideológicas (Re, 2005: 150). En este contexto, la pobreza, los desastres naturales, las guerras y el despojo de tierras han contribuido al desplazamiento de individuos y familias de comunidades indígenas hacia los centros urbanos, con lo que se han reconfigurado las nociones indígenas sobre la tenencia de la tierra, los papeles de género y las creencias religiosas. El análisis de estas modificaciones requiere repensar también los conceptos antropológicos y métodos que tradicionalmente se han utilizado para estudiar a las comunidades indígenas (Castellanos, 2012: 3).

Además del despojo de las tierras agrícolas es evidente el abandono, pues muchos trabajadores del campo han dejado la agricultura, bien de manera voluntaria u obligados a hacerlo como resultado de los cambios en las políticas públicas y el escaso apoyo que reciben por parte de los programas gubernamentales mexicanos. En Canadá, la amenaza de sustitución de mano de obra como un mecanismo de control no es nueva, las empresas utilizan esta práctica para disciplinar a los migrantes e intimidar a los representantes oficiales. Los empleadores han ejercido su poder para escoger el país que les abastece de mano de obra, advirtiendo a los socios bilaterales del PTAT que elegirán un nuevo país ante la presión sobre un mejoramiento en la remuneración y las condiciones de empleo; el acceso a la mano de obra global limita la posibilidad de que grupos de trabajadores, o el país proveedor, fomenten su poder de negociación (Preibisch, 2015: 122), por ello, es clara la política de desarticulación de los movimientos de trabajadores agrícolas temporales que pugnan por la creación de sindicatos. 
Cabe subrayar también que existen diversas investigaciones sobre el PTAT (Verduzco, 2004, 2007a, 2007b, 2008), e inclusive sobre poblaciones específicas, como la de los campesinos sinaloenses (Gámez, 2009). En general, dichos estudios se han centrado en la condición laboral, y en el proceso de envío de remesas por parte de los varones trabajadores a México. ${ }^{2}$

Como se sabe, el PTAT inició sus operaciones en 1974. Para participar es necesario ser campesino y habitar en un medio rural; tener entre 22 y 45 años. Para los varones se requiere ser casado (o vivir en unión libre) y tener hijos. Las mujeres pueden ser madres solas, viudas o divorciadas. Eventualmente se aceptan solteros/ as, pero deben demostrar dependientes económicos, lo cual permite suponer que retornarán a México. Cabe mencionar que el porcentaje de mujeres corresponde al 4\% del total de mexicanos que participan en el PTAT (Becerril, 2011: 25).

En abril de 2013 se incorporaron algunas medidas legales para ordenar y limitar la entrada de trabajadores agrícolas temporales a Canadá, entre ellas, la atribución al gobierno federal para que, en cualquier momento, pudiera suspender los permisos del PTAT; la imposición de un pago por la obtención del permiso de trabajo, el cobro de tarifas suplementarias a los empleadores que prefieran contratar trabajadores extranjeros sobre nacionales, y la obligación de demostrar que no existe mano de obra calificada canadiense para laborar en los campos agrícolas, pues, al parecer, existen demandas de ciudadanos contra ciertas granjas que se inclinan por emplear extranjeros (Radio Canada, 2013); ${ }^{3}$ no obstante, es sabido, que las labores agrícolas no son especialmente solicitadas por los canadienses.

En cuanto al PTAT en Quebec, se puede apreciar (Tabla 1) la distribución de campechanos, yucatecos y quintanarroenses que laboraron entre 2007 y 2014 en esa provincia. Los municipios que más aportaron mano de obra en el estado de Campeche fueron Calkiní, Hecelchakán, Champotón, Hopelchén y Campeche (Tabla 2). Los yucatecos eran originarios de 29 municipios, entre los que destacan Dzilam González, Dzidzantún, Valladolid, Maxcanú, Maní, Izamal y Mama (Tabla 3). Hasta 2011, los de Quintana Roo eran todos nacidos (o avecindados) ${ }^{4}$ en Othón P. Blanco (Tabla 4). Entre quienes entrevisté se encuentran ocho varones (Tablas 5 y 6), y en el grupo de informantes clave están cuatro mujeres, dos son trabajadoras, y dos, esposas de migrantes (Tabla 7).

\footnotetext{
${ }^{2}$ Entre los estudios que han incorporado el análisis de género se encuentran los aquí citados de Ofelia Becerril $(1995,2011)$.

3 "Ottawa annonce une reforme du programme des travailleurs étrangers", 29 de abril de 2013, Radio-Canadá, <http://www.radio-canada.ca/nouvelles/Economie/2013/04/003-changements-programme-travailleurs-etrangers-canada.shtml>

${ }^{4}$ La Secretaría del Trabajo no me proporcionó información sobre el lugar de nacimiento de los trabajadores; sin embargo, todos los entrevistados en Yucatán nacieron en el mismo estado, según ellos mismos confirmaron. De los que habitan en Quintana Roo, uno es de Tabasco, otro de Veracruz, y sólo uno nació en Chetumal.
} 


\begin{tabular}{|l|c|c|c|c|c|c|c|c|}
\hline & 2007 & 2008 & 2009 & 2010 & 2011 & 2012 & 2013 & 2014 \\
\hline $\begin{array}{l}\text { Total mexicanos } \\
\text { en PTAT Canadá }\end{array}$ & 11,864 & 15,848 & 15,352 & 15,809 & 16,492 & 17,626 & $18,500^{*}$ & $20,339^{* * *}$ \\
\hline $\begin{array}{l}\text { Total peninsulares } \\
\text { en Quebec }\end{array}$ & 70 & 89 & 91 & 85 & 110 & 132 & 141 & 179 \\
\hline $\begin{array}{l}\text { Campechanos } \\
\text { PTAT en Quebec }\end{array}$ & 30 & 41 & 46 & 41 & 44 & 48 & $59^{* * * * * *}$ & 67 \\
\hline $\begin{array}{l}\text { Yucatecos PTAT } \\
\text { en Quebec }\end{array}$ & 29 & 34 & 32 & 35 & 51 & 63 & 50 & 63 \\
\hline $\begin{array}{l}\text { Quintanarroenses } \\
\text { PTAT en Quebec }\end{array}$ & 11 & 14 & 13 & 9 & 15 & 21 & 32 & $49^{* * * * * *}$ \\
\hline
\end{tabular}

TABLA 1. Participantes de Yucatán, Quintana Roo y Campeche en el Programa de Trabajadores Agrícolas Temporales (PTAT) 2007-20014.

Fuentes: Tabla elaborada a partir del cálculo del Cuadro Programa de Trabajadores Agrícolas Temporales México-Canadá (PTAT), por entidad de residencia, 2003-2013. Base de datos de la Secretaría de Gobernación. En <http://www.omi.gob.mx/es/OMI/Tablas_PTAT> (acceso: 17 de mayo de 2013).

* Datos estimados en la página Web "Gobierno de Canadá" PTAT en <http://www.canadainternational. gc.ca/mexico-mexique/bilat/70Ann_U_canada_inmigracion.aspx?lang =spa > (26-05-15).

*** Datos estimados con base en información de "Programas de apoyo al empleo y la capacitación", Comisión Nacional de los Salarios Mínimos. En: http://conasami.gob.mx (26-05-15).

粎 Solo una es mujer.

\begin{tabular}{|l|c|c|}
\hline Municipios & Núm. de participantes por municipio & Núm. total de participantes \\
\hline Calkiní & 12 & 12 \\
\hline Hecelchakán & 8 & 8 \\
\hline $\begin{array}{l}\text { Champotón } \\
\text { Campeche } \\
\text { Hopelchén }\end{array}$ & 5 & 15 \\
\hline $\begin{array}{l}\text { Palizada } \\
\text { Escárcega }\end{array}$ & 3 & 6 \\
\hline Carmen & 2 & 2 \\
\hline Tenabo & 1 & 1 \\
\hline $\begin{array}{l}\text { TOTAL DE PAR- } \\
\text { TICIPANTES }\end{array}$ & & 44 \\
\hline
\end{tabular}

TABLA 2. Municipios de origen de los trabajadores del PTAT (Campeche) 2011. 


\begin{tabular}{|l|c|c|}
\hline \multicolumn{1}{|c|}{ Municipios } & $\begin{array}{c}\text { Núm. participantes } \\
\text { por municipio }\end{array}$ & Núm. total de participantes \\
\hline Dzilam González & 5 & 5 \\
\hline $\begin{array}{l}\text { Dzidzantún } \\
\text { Valladolid }\end{array}$ & 4 & 9 \\
\hline $\begin{array}{l}\text { Maxcanú } \\
\text { Maní } \\
\text { Izamal }\end{array}$ & 3 & 12 \\
\hline $\begin{array}{l}\text { Quintana Roo, Tekax, Tunkás, } \\
\text { Mama, San Felipe y Santa Elena }\end{array}$ & 2 & 17 \\
\hline $\begin{array}{l}\text { Cuncunul, Ticul, Tekit, } \\
\text { Sucilá, Sanahcat, Cacalchén, } \\
\text { Tixméhuac, Abalá, Opichén, } \\
\text { Buctzotz, Chichimilá, Tixkokob } \\
\text { Ixil, Chicxulub Pueblo, Tizimín, } \\
\text { Espita y Chacsinkín }\end{array}$ & 1 & 51 \\
\hline \begin{tabular}{l} 
TOTAL DE PARTICIPANTES \\
\hline
\end{tabular} & & \\
\hline
\end{tabular}

TABLA 3. Municipios de origen de los trabajadores del PTAT (Yucatán) 2011.

\begin{tabular}{|l|c|c|}
\hline \multicolumn{1}{|c|}{ Municipios } & $\begin{array}{c}\text { Núm. participantes } \\
\text { por municipio }\end{array}$ & $\begin{array}{c}\text { Núm. total } \\
\text { de participantes. }\end{array}$ \\
\hline Othón P. Blanco & 15 & 15 \\
\hline TOTAL DE PARTICIPANTES & & 15 \\
\hline
\end{tabular}

TABLA 4. Municipios de origen de los trabajadores del PTAT (Quintana Roo) 2011.

\begin{tabular}{|c|c|c|c|c|c|c|c|c|}
\hline Núm. & Seudónimo & Localidad & Edad & Escolaridad & Religión & $\begin{array}{c}\text { Núm. } \\
\text { de } \\
\text { hijos }\end{array}$ & $\begin{array}{c}\text { Años } \\
\text { de trabajo } \\
\text { en Quebec }\end{array}$ & $\begin{array}{c}\text { Granja } \\
\text { en la que } \\
\text { trabaja }\end{array}$ \\
\hline 1 & Jacinto & $\begin{array}{c}\text { Maní, } \\
\text { Yucatán }\end{array}$ & 39 & Secundaria & Católica & 2 & 8 & Le Claire \\
\hline 2 & Tomás & $\begin{array}{c}\text { Maní, } \\
\text { Yucatán }\end{array}$ & 39 & $\begin{array}{c}\text { Sin } \\
\text { escolaridad }\end{array}$ & Católica & 3 & 9 & Isabelle S-R \\
\hline 3 & Froilán & $\begin{array}{c}\text { Maní, } \\
\text { Yucatán }\end{array}$ & 36 & Secundaria & Católica & 3 & & $\begin{array}{c}\text { L'Assomption } \\
\text { Pépinière }\end{array}$ \\
\hline 4 & Felipe & $\begin{array}{c}\text { Mama, } \\
\text { Yucatán }\end{array}$ & 28 & Primaria & Católica & 2 & 5 & Isabelle S-R \\
\hline 6 & Basilio & $\begin{array}{c}\text { Dzidzantún, } \\
\text { Yucatán }\end{array}$ & 35 & Secundaria & Adventista & 5 & 7 & Le Claire \\
\hline
\end{tabular}




\begin{tabular}{|c|c|c|c|c|c|c|c|c|}
\hline Núm. & Seudónimo & Localidad & Edad & Escolaridad & Religión & $\begin{array}{c}\text { Núm. } \\
\text { de } \\
\text { hijos }\end{array}$ & $\begin{array}{c}\text { Años } \\
\text { de trabajo } \\
\text { en Quebec }\end{array}$ & $\begin{array}{c}\text { Granja } \\
\text { en la que } \\
\text { trabaja }\end{array}$ \\
\hline 7 & Raúl & $\begin{array}{c}\text { El Ramonal, } \\
\text { Othón P. } \\
\text { Blanco, } \\
\text { Quintana } \\
\text { Roo }\end{array}$ & 37 & Secundaria & Ninguna & 2 & 6 & $\begin{array}{c}\text { Les Fermes Du } \\
\text { Soleil S-R }\end{array}$ \\
\hline 8 & Ricardo & $\begin{array}{c}\text { El Ramonal, } \\
\text { Othón P. } \\
\text { Blanco, } \\
\text { Quintana } \\
\text { Roo }\end{array}$ & 34 & Secundaria & Católica & 2 & 6 & $\begin{array}{c}\text { Les Fermes Du } \\
\text { Soleil S-R }\end{array}$ \\
\hline
\end{tabular}

TABLA 5. Entrevistados en Yucatán y Quintana Roo que trabajaron en 2012 en Quebec.

\begin{tabular}{|c|c|c|c|c|c|c|c|c|}
\hline Núm. & Seudónimo & Localidad & Edad & Escolaridad & Religión & $\begin{array}{c}\text { Núm. } \\
\text { de hijos }\end{array}$ & $\begin{array}{c}\text { Años } \\
\text { de trabajo } \\
\text { en Quebec }\end{array}$ & $\begin{array}{c}\text { Granja } \\
\text { en la que } \\
\text { trabaja }\end{array}$ \\
\hline 1 & Diego & Opichén & 48 & Primaria & Católica & 4 & 6 & $\begin{array}{c}\text { L'Assomption } \\
\text { Pépinière }\end{array}$ \\
\hline 2 & Javier & Dzidzantún & 51 & Preparatoria & Católica & 3 & 7 & Isabelle \\
\hline 3 & Rodrigo & Tunkás & 38 & Secundaria & Católica & 3 & 8 & Legumiere \\
\hline
\end{tabular}

Tabla 6. Entrevistados en Quebec, trabajadores en 2012.

\begin{tabular}{|c|c|c|c|c|c|c|c|c|}
\hline Núm. & Seudónimo & Informante & Localidad & Edad & Escolaridad & Religión & $\begin{array}{c}\text { Núm. } \\
\text { de } \\
\text { hijos }\end{array}$ & $\begin{array}{c}\text { Estado } \\
\text { conyugal }\end{array}$ \\
\hline 1 & Karen & Esposa & Dzidzantún & 32 & Primaria & Adventista & 3 & Casada \\
\hline 2 & Rebeca & Esposa & Dzidzantún & 50 & Primaria & Católica & 5 & Casada \\
\hline 3 & Nelsy & Trabajadora & Dzidzantún & 41 & Bachillerato & Católica & 3 & Casada \\
\hline 4 & Noemy & Trabajadora & Dzidzantún & 42 & Bachillerato & Católica & 2 & Viuda \\
\hline 5 & Berenice & $\begin{array}{c}\text { Defensora } \\
\text { D.H. }\end{array}$ & Saint-Rémi & 35 & Licenciatura & N.D. & N.D. & N.D. \\
\hline 6 & Raymundo & $\begin{array}{r}\text { Defensor } \\
\text { D.H. }\end{array}$ & Saint-Rémi & 38 & Licenciatura & N.D. & N.D. & N.D. \\
\hline 7 & Josué & $\begin{array}{r}\text { Defensor } \\
\text { D.H. }\end{array}$ & Montreal & 37 & Secundaria & N.D. & N.D. & N.D. \\
\hline
\end{tabular}

TaBla 7. Informantes clave en Península de Yucatán y Quebec. 
Los migrantes que viajan sin pasaporte y visa hacia los Estados Unidos de Norteamérica eligen —dentro de ciertos límites- el lugar al que irán, a diferencia de los trabajadores del PTAT quienes no deciden en dónde trabajarán, ya que la granja de destino se determina al azar, dependiendo de la demanda. Ninguna de las personas que entrevisté sabía a qué lugar iría la primera vez (los años siguientes fueron solicitados mediante una lista nominal). ${ }^{5}$ Así, cuando llegaron a Quebec, desconocían completamente a qué tipo de sociedad se enfrentarían.

\section{El contexto de Quebec: migración, interculturalidad y accommodements raissonnables}

A partir de la década de los años sesenta del siglo xx, la política migratoria de Canadá dejó de dirigirse exclusivamente a la población europea (británicos, irlandeses, franceses, italianos) para incluir, sobre todo, a asiáticos y americanos (Choudry et al., 2009: 15); sin embargo, se puso poca atención en proporcionar un entrenamiento linguístico a los inmigrantes. Quebec transitó por un sendero diferente al del resto de Canadá, pues en el contexto de la denominada Revolución Tranquila (1960-1970), la sociedad empezó a reflexionar sobre sus rasgos de identidad, intentando diferenciarse de otras sociedades americanas, para destacar sus especificidades. Su sentido de diversidad se consolidó gracias al proceso masivo de instrucción de la población, lo que generó una fuerte conciencia identitaria, materializada en la música, el teatro y la literatura (López, 2000: 535). Aunque, sin duda, el rasgo característico de identidad es el idioma francés y su pertinaz defensa como lengua oficial de la provincia. Para armonizar las relaciones interétnicas, en 2001 se creó el Conseil Interculturel de Montréal, cuyos objetivos eran favorecer la integración ${ }^{6}$ y participación de los miembros de las distintas comunidades culturales (étnicas) en la vida política y económica de la ciudad; externar recomendaciones para el mejor funcionamiento, atender las exigencias de cualquier persona perteneciente a la comunidad cultural y hacer

\footnotetext{
${ }^{5}$ Los trabajadores regresan, casi siempre, a la misma granja, de acuerdo con una lista emitida por los patrones. El nombre es omitido si el trabajador tuvo un "mal comportamiento" en la temporada anterior, en cuyo caso, puede solicitar ir a otra granja o provincia, pero sin garantía de poder lograrlo.

${ }^{6}$ En este trabajo utilizo el concepto "integración” en el sentido que la sociedad quebequense le confiere, es decir, como accomodement raissonable (acomodamiento razonable), es decir, la adaptación de los inmigrantes de diferentes nacionalidades, religiones e ideologías a las normas y principios sociales y culturales de la sociedad de Quebec. En México, el concepto de integración consistió en "asimilar" a los grupos étnicos a una identidad nacional. Incluso, a inicios del siglo xx, estudiosos del indigenismo plantearon llevar población "blanca” a las comunidades rurales para acelerar la dinámica del mestizaje biológico y cultural, y contribuir a la consolidación de la identidad nacional. A pesar de los diversos intentos por "mexicanizar" u homogeneizar a la población, las distintas etnias indígenas mexicanas han resistido y conservan buena parte de sus concepciones ancestrales en torno a la organización política, social, económica y religiosa, así como usos y costumbres de la vida cotidiana (Rosales, 2010: 154).
} 
efectivas las investigaciones que pudiesen resultar útiles para la sociedad. Con ello, se pretendía que la población, específicamente de Montreal (en la que habita más del $70 \%$ de los inmigrantes) se uniese para discutir temas de diversidad etnocultural en todos los planos, y consolidar así una política de contratación laboral que asegurase la igualdad de los trabajadores. $\mathrm{Al}$ mismo tiempo, se deseaba que la ciudad fuese líder en el campo de la lucha contra la exclusión y el racismo, y favoreciera la prestación de servicios abiertos a la multiculturalidad, accesibles y eficaces para toda la comunidad. El foco en esta comisión especial era reiterar el compromiso existente con el interculturalismo vigente en Quebec, basado en el respeto y la comprensión de las diferencias.

En este contexto, en febrero de 2007, el primer Ministro de Quebec Jean Charest, anunció la creación de la Commission de consultation sur les pratiques d'accommodements reliés aux différences culturelles (Conseil Interculturel de Montréal, 2007), con la finalidad de investigar sobre diferentes prácticas culturales, mediante encuestas y sondeos realizados a ciudadanos de la provincia. Dicha comisión se encarga, desde entonces, de emitir recomendaciones al gobierno para que a través del sistema de accommodements raisonnables se respeten los valores comunes de Quebec, construidos en un largo proceso histórico. A dicho sistema puede dirigirse cualquier inmigrante que considere vulnerados sus derechos, pero que, al mismo tiempo, desea integrarse a la sociedad quebequesa. El concepto de accommodements raisonnables se refiere a culturas en negociación, a una reciprocidad y una responsabilidad de ambas partes; no implica la aparición de nuevos derechos colectivos, pues involucra no sólo a inmigrantes sino también a grupos minoritarios que se han visto discriminados por ser poblaciones originarias o por motivos religiosos, entre otros.

Así, en Quebec, la interculturalidad tiene como objetivo la comunicación entre culturas, a través, sobre todo, de su idioma oficial, el francés. Para combatir la marginación de las comunidades culturales, se considera relevante el apoyo mutuo entre las organizaciones comunitarias y la acción municipal. En ese sentido, en 2006 se instituyó la Charte Montréalaise des Droits et des Responsabilités (Service du Capital Humaine et des Communications, Direction du Greffe à la Direction Générale, 2012) como instrumento de derechos humanos que favorece la inclusión social, la eliminación de la discriminación, la vida democrática y el respeto de la dignidad humana.

Aunque cabe mencionar que gran parte de los avances en materia de interculturalidad y reconocimiento de la diversidad se deben a los logros de la Revolución Tranquila - a partir de la cual se comprende el fuerte sentido de identidad de la sociedad francófona quebequense- en particular en cuanto a igualdad entre hombres y mujeres, y la separación entre política y religión (Conseil Interculturel de Montréal, ibid., 25). Pero la paradoja de la interculturalidad quebequense es que como sociedad receptora de migrantes debe lidiar con ideas, creencias, valores, rituales, usos y costumbres de las culturas originarias y, respetar esa diversidad en el marco de la herencia ideológica de la Revolución Tranquila: je me 
souviens. Es decir, se lucha por las diferencias, en el contexto de la batalla que se libra cotidianamente por mantener la identidad.

En esta trama de incesante afirmación de la identidad quebequense, quizás sea injusto decir que los inmigrantes agrícolas temporales son invisibilizados o excluidos, al no existir una política pública destinada a velar por sus derechos, su inclusión en la sociedad, y la promoción de la enseñanza del idioma francés; mas considero que esta situación es parte de la paradoja que implica la pertinaz defensa de la propia identidad, y el reconocimiento de la diversidad cultural en la unidad. Otros aspectos que parecen contradecir el carácter intercultural -entendido como un diálogo entre culturas distintas- de la sociedad quebequense son que no existe un programa de certificación de las competencias para los trabajadores agrícolas, pues se da por hecho que no solicitarán su estancia permanente; no se respeta su derecho de antigüedad, al ser decisión del empleador solicitar o no al empleado en la siguiente temporada; las condiciones de vivienda, en algunos casos, son deplorables; muchas veces son tratados como convictos o menores de edad, ya que el dueño de la granja (o uno de sus representantes) se encarga de trasladarlos (en autobús, camioneta o auto) y permanece con ellos mientras hacen sus compras. Además, en el primer trimestre de 2013, se suprimió la prestación por paternidad o maternidad que se otorgaba a los trabajadores del Programa de Trabajadores Agrícolas Temporales (PTAT).

En este contexto de vulneración de los derechos de los trabajadores, surge la pregunta de si es factible el respeto de las diferencias cuando se está en proceso de afirmar la propia identidad. El discurso sobre la interculturalidad en Quebec es incluyente, la práctica no lo es, no al menos para quienes laboran en las granjas de manera no permanente. Es más, en la integración que se persigue para los inmigrantes a través de los denominados accommodements raisonnables no están incluidos los trabajadores agrícolas temporales; no hay conflicto con ellos, pues se sabe que retornarán a sus lugares de origen.

\section{La milpa como "espacio practicado" en Yucatán: "toda la creencia está allá”}

La cultura maya es apreciada en distintos contextos nacionales e internacionales; no obstante en Quebec, al menos en 2012, el interés estaba en conocer sobre las mal llamadas profecías mayas que predecían el fin del mundo. En espacios nacionales, como Cancún, la parafernalia cultural del mercado turístico es sumamente distinta de la que acompaña a los inmigrantes mayas (Re, 2005: 150), pues la ocupación laboral los coloca en una estructura social clasista, tanto en el interior de la etnia, como en el conjunto nacional. No obstante, un grupo privilegiado de mayas consiguió la prosperidad económica en esa ciudad, a la que se mira como una esplendorosa milpa que les provee de negocios y capital (ibid., 156). Otros mayas menos favorecidos han encontrado senderos alternativos para conseguir 
el bienestar económico, como aquellos que se ven inmersos en procesos de migración temporal internacional y que participan en el PTAT.

Para explorar las experiencias del proceso migratorio de los trabajadores de la península de Yucatán en los campos agrícolas quebequenses, considero útil la distinción que hace Michel De Certau de "espacios y lugares":

Un lugar es el orden (cualquiera que sea) según el cual los elementos se distribuyen en relaciones de coexistencia. Ahí pues se excluye la posibilidad para que dos cosas se encuentren en el mismo sitio [mientras que] el espacio es un cruzamiento de movilidades (...), a diferencia del lugar, carece pues de la univocidad y de la estabilidad de un sitio propio. En suma, el espacio es un lugar practicado (...) [que] se transforma en espacio por intervención de los caminantes (...) Los relatos efectúan pues un trabajo que, incesantemente, transforma los lugares en espacios o los espacios en lugares (2000: 129-130).

Los trabajadores agrícolas temporales yucatecos no logran transformar el lugar de la granja quebequense en un espacio, entendido éste como un "cruzamiento de movilidades" o un "lugar practicado", pues al vivir allá permanecen en un estado de desconexión de su cultura, sus comunidades, sus familias, su ambiente; se encuentran en impasse en un sitio que no les confiere espacio.

Entre los mayas de Yucatán, la milpa como "espacio practicado" representa el vínculo con la tierra; es relevante conservar la milpa y los espacios naturales, pues de ellos se obtienen productos animales y vegetales útiles para la subsistencia diaria. De hecho, la palabra "conservar" tiene un doble significado, por un lado, en el sentido de cuidar o atender la tierra, y por otro, en el de preservar (ser dueños), pues "para ellos la tierra ha sido el medio vital de existencia, el patrimonio más valioso (...) Desde el inicio de la colonización española, el esfuerzo por conservar las tierras de comunidad se convirtió en una bandera de lucha, en un fundamento ético de su identidad y de su autonomía individual y colectiva" (Alejos, 1992: 167). Esto es claro en el siguiente testimonio:

De noche estamos hablando, el mismo duende, él te va a traer el venado para que tú lo puedas cazar, en menos de una hora, el duende ya te lo trajo, ¿por qué? porque ya le diste un cigarro. Bueno, eso muchas personas así lo hacen, le llevan el cigarro, porque si no llevas el cigarro y nomás entras en un terreno, que no pides permiso, que no hablas con nadie y nomás te metes, no (...) Allá en mi pueblo, a un terreno no puedes solo meterte a cazar, a agarrar, tienes que pedir permiso antes, aunque no viva nadie, pero tienes que pedir un permiso, porque si nomás entras... es que en esta vida hay... el diablo... es como el aire, aire malo, no sabes si aquí lo cargué, o acá, o allá, no sabes donde, porque pasa en todos lados (Diego, Opichén, entrevistado en Quebec).

La milpa, y en general el monte, es un espacio que hay que respetar; a través de diversos rituales se pide permiso para ingresar a cazar, a sembrar, a extraer frutos o miel. Mediante el chaa chak se piden buenas lluvias para los cultivos; 
para el espacio practicado. Es diferente en Quebec, y no sólo por la existencia de sistemas de riego, como comentó uno de los informantes:

Lo hacemos, hace dos años lo hicimos, lo hicimos en su casa de mi hermano, no sé si supiste, el kool que le dicen... de los antiguos (...) no sé si llegaste a ver, vamos a suponer que este bote, le ponemos masa y la pasta roja... matamos como 12 pollos; pero nosotros no los matamos, el brujo los matan (...) pero antes de eso, antes que lo reparten [la comida] el brujo tiene que dar gracias a.... bueno, al dios de la lluvia; para que cuando vas a sembrar, ahí caiga el agua, para que no te quedes sin agua cuando estás sembrando, tiene que llegar el agua, tiene que llegar, por eso en las ceremonias se hace, en el mes de abril, abril y mayo, porque en junio ya hay agua por allá... Aquí no se hace así.

P: ¿No? ¿Aquí en esta granja tienen sistema de riego?

R: No.

P: Entonces aquí en Quebec, si hacen una ceremonia para pedir agua a los chaques icree que funcione?

R: Acá no, no, pues acá no conocen estos gringos de acá (risa). Acá si lo explicas nomás te van a hacer como a un lado, acá ni conocen qué es Dios, acá no; en cambio allá, como es... allá, pues toda la creencia está allá (Rodrigo, Tunkás, entrevistado en Quebec).

La dinámica social modifica ciertas concepciones culturales; unas prevalecen, y otras desaparecen. "Es diferente aquí y allá, por ejemplo, aquí mi suegro pide agua a los chaques en abril y mayo; pero yo no lo hago porque estoy en Quebec, y allá no se hace así. Aquí [en Maní] tengo sistema de riego, y así pues ya no necesito pedirle a los chaques" (Jacinto, entrevistado en Maní). Hay otros mayas que no celebran la ceremonia ni en su pueblo porque "dicen que es cosa del diablo, y desde que soy de la adventista, ya no lo hago así” (Basilio, Dzidzantún).

En Quebec, no se pide lluvia a los chaques, aunque no haya sistema de riego, pues otros miran con desconfianza sus ideas, y muchos, inclusive mexicanos, hacen mofa de ellas. En Yucatán, la incorporación de tecnologías de riego y la adscripción a otras religiones cristianas propician el abandono de ciertas prácticas rituales. No obstante, es interesante la percepción de la milpa, de la tierra, como un espacio "practicado"; finalmente, como dice Rodrigo, "toda la creencia está allá".

La mayoría de las prácticas culturales (rituales, fiestas religiosas, celebraciones, homenajes) en las que se involucran los informantes las desarrollan sólo en Yucatán. Por ejemplo, dicen que el hanal pixan allá "es como de Halloween más bien, pero de día de muertos no hacen un altar" (Tomás, Maní); "nosotros no ponemos ofrenda porque estamos trabajando, no hay tiempo" (Jacinto, Maní). Sólo en Yucatán se aparecen la Xtabay, los aluxes o el huay chivo:

Hay muchas historias por acá; allá en Quebec no. Aquí te acercas a un viejito... Bueno, antiguamente es así, pero ahorita como yo salgo y trabajo de albañil, ahorita casi no me junto con los viejitos, pero antiguamente como me llevaban en la 
milpa, ese animal está muy grande y te vas a sorprender porque es la primera vez que lo vas a ver, no lo puedes matar ni lo puedes tirar con piedras, es mejor hacerte a un lado. Ves que cruce y no lo vas a platicar cuando llegues en el pueblo, nada, pasando una semana, lo platicas, porque si lo tratas de tirar con rifle a que lo mates, al día siguiente te estás muriendo porque el animal trae un aire malo. Lo que pasó hace como seis años, se unieron como tres señores para matar a ese animal, ellos están tirando con el rifle, ipam! ipam! le están dando, pero el animal nada más se volteó a ver y siguió yendo. Al día siguiente murió uno, el otro se quedó inválido, el otro no podía hablar, los tres se murieron, no tardaron, en menos de tres meses se murieron los tres.

P: ¿Por qué después de una semana lo puedes platicar?

R: Porque... ¿cómo te diré? Todo el aire.. como sales cada rato hacia fuera, pues el aire está pegando, es como si fuera.. lo que se te pegó.. el aire se te va quitando otra vez, el mal. Ponte tú que un día de estos vas a ir a la misa, pues vas allá, sales y el aire te está pegando ¿no? Es como si ahorita... ahorita no tenemos aire, sales acá y sientes el aire que es fresco ¿no? y te pega y es como si fuera quitando el mal, que se vaya otra vez, pasa una semana y lo puedes platicar otra vez, bueno, eso dicen los señores antiguos ¿no? (Jacinto, entrevistado en Maní).

Se dice que cuando los perros ladran de manera insistente es porque anda por ahí un huay chivo, un huay pek o un huay mis, es decir, un brujo mitad hombre y mitad animal, generalmente negro — aunque puede ser blanco- con ojos rojos, que sólo sale de noche. Los habitantes de un pueblo han de protegerse en sus casas y tener cuidado de no exponerse a sus ataques, ya que este brujo, convertido en huay chivo, puede causar mucho daño a las personas, sobre todo a través de su "aire":

Y después viene contigo y te lamea [te lame] si es gato... si es huay mis te lamea el cuerpo, te roba tú alma, mejor dicho, y se convierte en tú, el animal. El huay pek tiene unas cadenas tan largas, lo jala, se escucha que lo está jalando pero no tiene cadenas sólo [se escucha] (...) Cada noche, cuando anochece, está pasando alguien así pero tiene como 10 cadenas agarradas, así tiene su mano el huay chivo y dicen que cuando habla le sale sangre de la boca, están rojos sus ojos. Cuando lo mira a uno así lo congela, a mi hermano cuando pasó el huay chivo irápido! se quedó hipnotizado, estaba hablando y ya no puedes hablar, en dos horas dijo se descongeló, dice que fue el aire (Tomás, entrevistado en Maní).

Porque tiene cruz y después le pones agua bendita, la dejas en tu puerta y cuando venga el huay chivo no te va a hacer nada, sólo ve que está ahí, y el aire del agua lo lleva lejos para que no regrese. Se pone como protección para que no entre y cuando lo puso así se lo llevó lejos; mi tío le dio agua bendita... dicen que todos los animales si son huay chivos tienen cabezas de hombres (...) si estás viendo te atrapa y te lleva a donde sea para que no salgas y te mueras, te tapa tu nariz para que te mueras rápido, quiere que te mueras para que te coma (Felipe, entrevistado en Mama).

Dicen que también sale por los caminos de mi abuelo allá lejos, lejos, dicen que salen muchos, y que hasta muertos reviven allá, pero quién sabe, que sale, que cuando no haces novena, dice mi tío, porque... nosotros no le hicimos novena a mi 
abuelo cuando se murió, sólo lo enterraron así simple (Froilán, Maní, entrevistado en Yucatán).

Estos relatos e interpretaciones de los informantes permiten sugerir que en Yucatán los espacios son "lugares practicados", a diferencia de Quebec, en donde el lugar se concibe sólo como uno para el trabajo, pues "toda la creencia se queda allá”.

\section{Espacios femeninos y relaciones de género: aquí y allá}

En las comunidades de la península de Yucatán, en las cuales realicé las entrevistas, se espera que los varones sean quienes trabajen fuera de casa para proporcionar la manutención a la familia. Mientras los hombres laboran en Quebec, las mujeres se encargan de administrar los recursos económicos, y de resolver los asuntos cotidianos que sus esposos no pueden gestionar durante ese tiempo; aunque eso no las exenta de realizar trabajos como bordado, costura, urdido de hamacas o labores agrícolas en la milpa o el huerto familiar. La vida no es sencilla, pero todos, mujeres e hijos, se van adaptando a la nueva realidad:

Él es agricultor pero para que él pueda hacer una producción pues se necesita invertir y eso es lo más difícil, como los niños están estudiando, pues es muy apretado. Él aquí se dedica a la milpa, ahorita sembró un poco de calabaza, pero no le fue muy bien que digamos; pero es jornalero, en donde le hablen [va] a chambear, a tumbar o a bajar productos de otras personas (Karen, esposa de migrante, Dzidzantún, Yucatán).

La verdad al principio era una situación muy difícil porque trabajaba y trabajaba [se refiere a su esposo] y no salíamos adelante; soy sincera, dejamos Yucatán y nos fuimos a Cancún, Quintana Roo, dos años, pensando que íbamos a mejorar. Trabajábamos los dos y ni así. Cuando regresamos a Dzidzantún, al poco tiempo salió esto. Desde que se fue, lo que ha enviado ha servido para construir; empezamos con un cuartito. Cuando llega a Yucatán busca trabajo, y así va saliendo. Hemos construido la casa. Yo he trabajado en tiendas, en molinos; lo dejo por mis hijas y mis nietos, y luego vuelvo. Pero desde que él se va, todo lo que gana mi esposo lo invierto, lo manda quincenal, me manda por Telecom o Western Union. Antes usábamos la tarjeta pero solo puedes retirar dos mil pesos (Rebeca, esposa de migrante, Dzidzantún, Yucatán).

Ante los constantes viajes cada año, las relaciones de pareja y con los hijos sufren cambios, ya que, en general, mujeres y hombres de las comunidades rurales de la península de Yucatán se rigen por la división sexual del trabajo, es decir, hay papeles de género definidos para cada uno. Las esposas comprenden que sus maridos se alejan para que la familia pueda tener mejores condiciones de vida, aunque ello implique enormes costos emocionales.

Hay que subrayar que ciertos elementos culturales (ideas, creencias, valores, prácticas, rituales) no son valorados y/o respetados en el contexto de trabajo en Quebec, por ello es mejor pensar que a Canadá se va a laborar, y que la familia y “toda la creencia está allá” en Yucatán: 
Cuando se dio cuenta de que solo iba a trabajar sintió tristeza; cuando regresa disfruta mucho a sus hijos, dice que tiene que aprender psicológicamente que va a trabajar. Dice que prefiere no pensar en Yucatán cuando está allá. Prefiere pensar lo que va a hacer de su trabajo, y pensar positivamente para no sentir tan feo. De aquí se llevó fotos y música para no extrañarnos tanto (Rebeca, esposa de migrante, Dzidzantún, Yucatán).

Lleva fotos, su ropa de frío, de trabajo; al principio cuando venía se traía todo, pero ahora ya lo deja allá. Lo separa su trabajo de acá. Ya lo veo mejor, antes se ponía más triste cuando se iba. Lo veo mejor porque acá tenía mucha presión por lo económico, en cambió así está más desahogado. Y pues yo sí me siento triste, pero es lo mejor para la familia que él trabaje allá (Karen, esposa de migrante, Dzidzantún, Yucatán).

Hasta el año de 2012, entre los migrantes agrícolas temporales de la península de Yucatán que trabajaban en Quebec, no había mujeres. Las dos entrevistadas en 2013 laboraban en Vancouver y ambas son de Dzidzantún. De acuerdo con registros proporcionados por la Secretaría del Trabajo, en 2013 acudió a Quebec una mujer de Escárcega, Campeche, quien no volvió en 2014, y en ese mismo año viajó otra mujer de La Rovirosa, municipio de Othón P. Blanco, Quintana Roo. De las entrevistadas, una trabajaba en la recolección de manzana, y otra en una empacadora de cerezas, de 10 a 12 horas por día. Una de ellas va por dos meses y la otra por cuatro, en contraste con los varones que se van por un período promedio de ocho meses. Sus condiciones de vida no distan mucho de la de los hombres, ya que también son confinadas en caserones con espacio insuficiente:

En la farma somos como 60; vivo en un galerón donde hay camas, ahí solo hay mujeres, como 17 mujeres (...) tenemos cuatro baños, cada uno tiene cuatro tazas y una regadera. Tenemos burós para poner nuestras cosas; la cocina es grande (Nelsy, trabajadora en Vancouver, Dzidzantún, Yucatán).

Yo ya me acostumbré, después de dos años; no podemos exigir, hemos hablado con el patrón, y dice que le gustaría mejorar las condiciones pero no puede. Los baños se fregaron, salía agua, a ver si mejora. En cada cuarto hay dos camas, somos dos por cuarto; hay tres baños para 20 personas y solo hay dos regaderas. No es suficiente, cuanto te quieres bañar te tienes que esperar a la madrugada, pero si te toca el aseo pues ya no te bañaste. Los cuartos no tienen calefacción pero [cuando ella va] no hace mucho frío. (Noemy, trabajadora en Vancouver, Dzidzantún, Yucatán).

En cuanto a las relaciones laborales, una de ellas comentó que debía viajar 30 minutos en un autobús para llegar a su lugar de trabajo, y que el espacio era insuficiente, y la otra que si quería ir al baño debía pedir permiso, pero si tardaba más de 15 minutos el tiempo le era descontado de su salario. Ninguna habla inglés así que "no podemos pelear por esos derechos o siquiera preguntar" (Noemy). Si hay necesidad de acudir a los servicios de salud no tienen claridad de cómo hacerlo, y las condiciones en el lugar de trabajo pueden generar la aparición de ciertas enfermedades: 
Esta vez se enfermaron muchas; trabajamos dentro de un túnel y hay mucho frío. Muchas no aguantaron, te tenías que poner hasta tres abrigos; les dio gripa o se lastimaron por lo que le ponen a la fruta. Se tardaban dos o tres días de reposo, a varias se les hincharon los ojos por el agua de la fruta. Además te ponen guantes de látex que son más fríos; es horrible (Noemy, trabajadora en Vancouver, Dzidzantún, Yucatán).

Por otro lado, refirieron que no se respetan sus días de descanso, pues si se requiere deben trabajar todos los días de la semana con horarios largos: "le dijimos al capataz ¿y cuándo vamos a descansar? Y él dijo "hoy van a trabajar y mañana descansan; además, hoy vamos a comer pizza'" (Noemy, trabajadora en Vancouver, Dzidzantún, Yucatán).

Tanto los hombres como las mujeres trabajadoras y las parejas de los migrantes atraviesan por procesos que modifican sus relaciones de género en el contexto del PTAT. Los varones realizan actividades similares a las que desarrollan en sus lugares de origen, como ir al bar, a jugar futbol o a "pasar el tiempo" con los amigos, además de cocinar, lavar y limpiar sus viviendas, cosas que no hacen en sus comunidades:

Que trabajen ellos mismos siento que los sensibiliza para el trabajo del hogar y lo valoran; siempre dicen: "no pues es que aquí estoy solo y está cabrón”, y digo pues sí, y yo mismo lo veo, pues pobrecitos ino? ya te echaste una jornada de 12 horas y llega a hacerte tus frijoles... está pesado (Josué, defensor de los derechos humanos de los trabajadores sin papeles en Quebec).

Las mujeres, además de cumplir con su trabajo y tareas domésticas, tienen un poco de más libertad allá para salir con sus amistades y para entablar algún tipo de relación:

Los hombres se van a encontrar en la cancha de futbol, en el bar y en los lugares recreativos digamos ino? va a haber compañeros que hablan con las mujeres y mujeres que van a aceptar a hablar. De hecho, hasta encuentran bien guapos a los mexicanos e interesantes porque bailan; son mucho más calurosos, están menos espantados que el quebequense. La mujer está bien empoderada aquí, el quebequense dice mmm no, tú tus cosas, yo las mías. Y el mexicano no; aunque no tenga dinero: "yo te invito guiera", y ahí andan, consintiéndolas (Raymundo, defensor de los derechos humanos de los trabajadores agrícolas temporales en la región de Saint Rémi, Quebec).

Sin embargo, debido a la condición de ser un migrante, desarrollar vínculos afectivos puede ser problemático, e inclusive ocasionar el cese del contrato y la pérdida del estatus de trabajador temporal, además de generar conflictos con las autoridades locales:

Como había una restricción, una orden de la corte de que no se podía acercar a ella, iah! pues ella [una quebequense] se acercaba a dónde estaba él; solo para lograr que criminalmente lo pudieran expulsar del país. Entonces, esa es la otra cara de la mo- 
neda ¿no? Otro se enredó con una chica salvadoreña, e igual, promesas, años y años de venir y para allá y para acá, hasta el día que ella dijo: “ya basta”, y le habló a la mujer [la esposa en México]. Se hizo un problema de aquellos. Luego, éste se quiso zafar y no se dejó, o sea ella no se dejaba, e iba a la finca, total que en este caso fue el trabajador el que tuvo que pedir a la corte una sentencia provisional para que ella se mantuviera a cierta distancia, e igual el consulado actuó en buena forma, y lo transfirieron a otra finca para solventar el problema. Ellos no piensan que están así las mujeres aquí, tan fuertes, que tienen tanto poder, ni se han dado cuenta de eso, pero por eso acaban en el bote (Raymundo, defensor de los derechos humanos de los trabajadores agrícolas temporales en la región de Saint Rémi, Quebec).

Otra situación es que ante el proceso de la migración, las esposas (quienes se quedan en las comunidades) se sienten amenazadas por la idea de que sus parejas serán infieles en Canadá. Obviamente existen distintas realidades al respecto, entre ellas, las de los que sí se involucran con otras mujeres:

Porque ha habido casos también de allá, de que ya la mujer dice: "no pues tú ya andas allá, pues sáquese”. Entonces ya vienen aquellos llore y llore, y entonces ya uno se vuelve como asesor psicológico, porque pues está ahí contándome del divorcio y pues yo les digo: compa, ¿la quieres?” —-"sí”. Pues vaya y pídale perdón, actúe, no se puede quedar llorando toda la vida y menos aquí porque lo primordial es... pues aquí, estar en su trabajo compa. Entonces concéntrese porque pues ya tronó allá, lo van a tronar aquí, entonces piense que va a hacer cuando llegue a México (Raymundo, defensor de los derechos humanos de los trabajadores agrícolas temporales en la región de Saint Rémi, Quebec).

En general, tanto hombres como mujeres expresan que deben tratar de cuidar el tipo de relación que establecen con compañeros, capataces, administradores y propietarios, pues de ello depende que puedan volver la siguiente temporada. De esta manera se sienten protegidos y seguros en cada espacio en el que se desenvuelven. A Canadá se va a trabajar; en su comunidad de origen pueden sostener vínculos afectivos, expresar sentimientos, ideas, valores y creencias que en otro lugar están fuera de contexto.

\section{El campo agrícola como lugar de trabajo en Quebec}

En Quebec “cuando platico de la creencia, me dicen: 'todo eso, todo eso, nosotros no conocemos; sabemos que se va a acabar el mundo maya, de ahí salió el fin del mundo [se refieren a diciembre de 2012], ${ }^{7}$ y yo digo, solo Dios sabe, verdad" (Diego, Opichén, entrevistado en Quebec). Sin los aluxes, la Xtabay o el huay pek, los yucatecos y quintanarroenses que participan en el PTAT prefieren

\footnotetext{
${ }^{7}$ Fecha en que supuestamente se acabaría el mundo, con base en una errónea interpretación de la concepción maya del Baktún 13.
} 
concentrarse en el trabajo y no pensar mucho en sus comunidades y familiares; pues finalmente "toda la creencia está allá".

En la provincia canadiense los trabajadores cuentan con tractores, camionetas y camiones que les facilitan sus labores en los campos agrícolas, en los cuales siembran y cosechan uva, frambuesa, zarzamora, arándano, brócoli, betabel, rábano, cebolla, papa, zanahoria, entre otros. En algunos lugares hay invernaderos en donde cultivan vegetales como jitomate, lechuga, cilantro y pepino, y frutos como fresa y cereza, e inclusive flores (Figura 1).

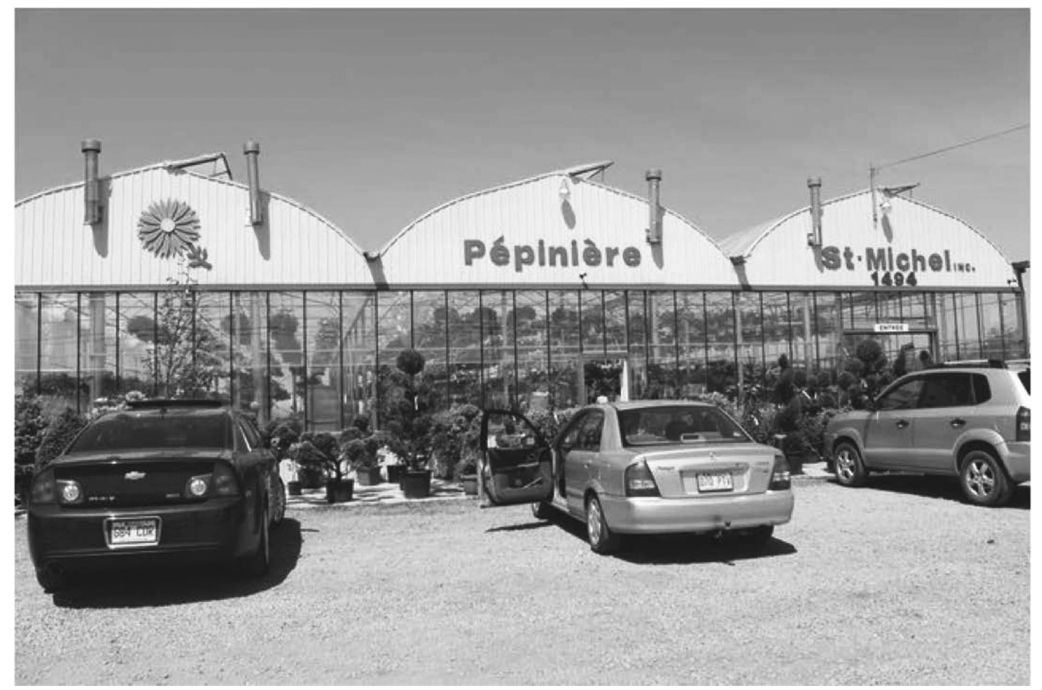

FIGURA 1. Vivero Pépinière Saint-Michel,

condado de Les Jardins de Napierville, provincia de Quebec.

Fotografía de Adriana Rosales.

Los participantes del PTAT viven dentro de las granjas o cerca de ellas, en casas o trailas (tráiler), como les llaman, en donde pueden cohabitar hasta 40 personas, comúnmente en cuartos para dos (Figuras 2 y 3). En general, cuentan con todos los servicios, camas, roperos, refrigerador, estufa, horno de microondas, lavadora y secadora. Las horas de trabajo son variables, dependiendo de las necesidades de la granja y del clima, ya que si llueve no pueden acudir al campo. Si el patrón quiere recuperarse del clima y aumentar la producción, tendrán que pasar hasta 14 horas en la plantación o 18 en una bodega, con dos descansos de entre diez y 30 minutos, y una hora para comer. El salario que perciben es de $\$ 10.25$ dólares canadienses por hora, ${ }^{8}$ y no tienen derecho a pago suplementario por horas extras o por laborar en sábados y domingos, con algunas excepciones:

${ }^{8}$ En 2012. 


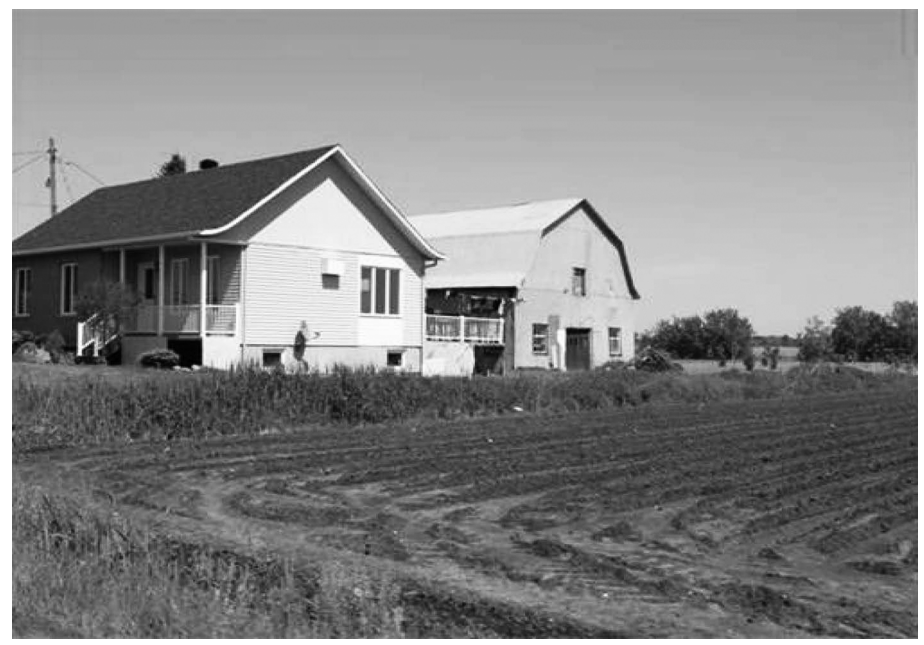

Figura 2. Granja en la Región de Saint-Rémi, Quebec.

Fotografía de la autora.

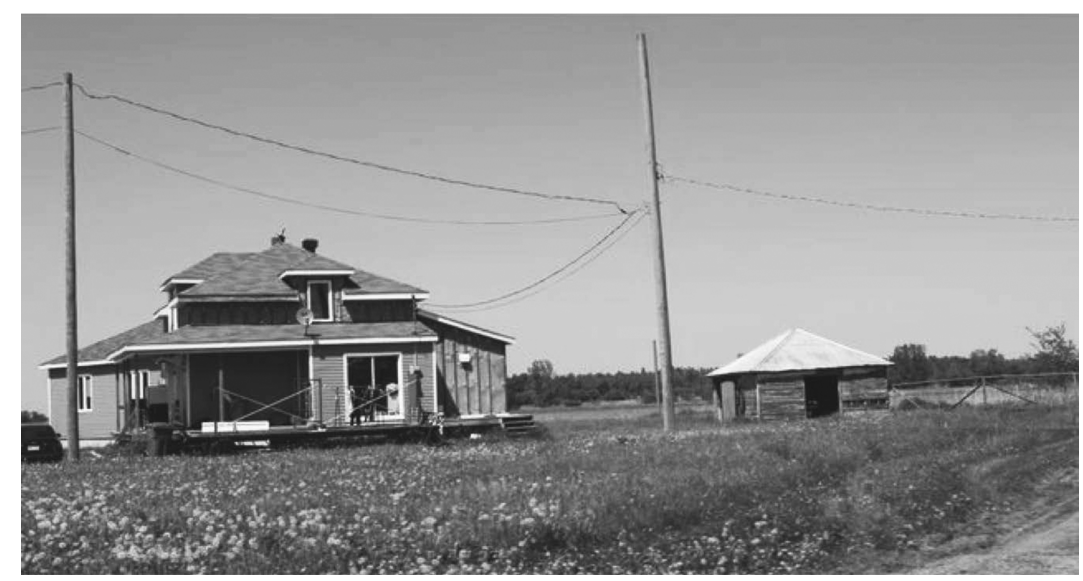

Figura 3. Casa habitación de trabajadores agrícolas temporales en los alrededores de Saint-Rémi. Fotografía de la autora.

Tiene su tiempo en que hay más horas... Lo normal, ocho o diez horas, pero en donde yo trabajaba en las farmas [granja, en francés ferme] hubo días que trabajábamos 17 horas. Hubo un día que [el patrón] necesitaba un pedido y tenía que sacarlo, trabajamos 32 horas, nada más dormimos de cuatro de la mañana a ocho, en Vancouver. En cambio en Quebec solo trabajas diez horas, once horas; los domingos nada más por cuatro o cinco horas. En la farma donde estoy ahorita (...) si trabajas días de descanso, te pagan doble, extras; en Quebec. En Vancouver no nos pagaban, no nos reconocían ni una hora extra aunque trabajáramos de noche, nos pagaban normal nuestros nueve dólares. Hay como dos o tres provincias que pagan más (Basilio, Dzidzantún, entrevistado en Yucatán). 
La experiencia de Basilio fue excepcional, ya que los derechos laborales de los participantes en el PTAT están regulados por Les normes du travail au Québec en donde se estipula que los contratados en campos agrícolas no cobrarán el $50 \%$ suplementario al salario que marca la ley por horas extras (Commission des Normes du Travail de Quebec, 2014: 9), lo que quiere decir que se les pagará la misma tarifa por hora trabajada, independientemente del tiempo que laboren por día, aun si es domingo. Esto, a pesar de estar contemplado en dicha norma, representa una violación al derecho que toda persona tiene al descanso y a una compensación por horas extras. No obstante, para ninguno de los entrevistados es un problema dedicar más tiempo de lo estipulado a una jornada laboral, pues si trabajan más, ganan más. Lo que menos quieren es permanecer en la casa o el tráiler a causa del mal clima, o porque no hay trabajo suficiente en la granja. De cualquier manera, las condiciones son diferentes para los quebequenses y los yucatecos, y en general para los mexicanos y los guatemaltecos, que constituyen la mayoría empleada en estas granjas agrícolas:

Los canadienses tienen un contrato con el gobierno; ellos no se pueden pasar de ocho diarias en cinco días. Si no tienen trabajo les dan el seguro de desempleo, a los seis meses les dan su seguro (...) ¿por qué a nosotros no se nos da ese beneficio de los meses que no trabajamos? Ellos no hacen el trabajo igual que nosotros, no cargan igual que nosotros, no desyerban igual que nosotros (...) Yo estoy ejerciendo mis derechos y no voy a dejar que me estén arrastrando (...) Pero en México nos dicen, saben qué señores, cuiden a sus patrones; su trabajo, si no... (Javier, Dzidzantún, entrevistado en Yucatán y en Quebec).

Una de las quejas más comunes sobre el ambiente de trabajo se refiere a la presión que padecen por parte de los capataces (y a veces, patrones) en términos de aumentar la productividad. La mayoría de los entrevistados comentó a propósito de la tensión en que se ven inmersos por la demanda de realizar su trabajo con mayor rapidez, y en menos casos, sobre algún mal trato por parte de sus superiores. "En Quebec cuando el patrón se dirigía a nosotros era para reprocharnos el trabajo o un regaño, pero no para saludarte, ni siquiera los buenos días" (Raúl, El Ramonal, Othón P. Blanco, entrevistado en Quintana Roo).

Isabelle, se llama así. Esa "farma" es grandísima, a veces trabajamos 13 o 14 horas, y las personas no quieren ir en la empacadora porque hay gran presión. Mi patrón quiere cantidad no calidad, y en la granja yo soy el de mayor edad, y a mi patrón le digo, a ver voy a trabajar más, pero estás forzando la máquina. Entonces yo le digo a mi patrón, si no hacemos bien las cosas [se refiere a empacar] las van a rechazar, hay que escoger bien (Javier, Dzidzantún, entrevistado en Yucatán y Quebec).

A veces, algunos de los capataces nos exigen mucho, ellos son mayormente canadienses, a veces nos sentimos un poco mal, pero para eso trabajamos; los mayordomos son los que nos dicen que trabajemos más rápido, nosotros les decimos a los dueños, y ellos les llaman la atención, pero los mayordomos más se molestan (Felipe, entrevistado en Mama). 
Hay muchas quejas porque a veces se pide que trabajen un poco más, el capataz pide que trabajen un poquito más rápido, pero eso es a los que se imponen. La verdad vamos a trabajar, para mí no es una presión, te lo dicen en buenas palabras (Ricardo, El Ramonal, Othón P. Blanco, entrevistado en Quintana Roo).

Por otro lado, los entrevistados expresaron el temor de ser deportados o no ser solicitados en la lista nominal de la siguiente temporada, en caso de denunciar los malos tratos que reciben, el poco tiempo de descanso que tienen en medio de las largas jornadas laborales a las que están sujetos, o las malas condiciones en las que viven en las casas y los tráilers proporcionados por sus empleadores. Una cosa que no mencionaron, pero que salta a la vista, es la poca libertad de la que gozan para salir, e inclusive para acudir a realizar sus compras e interactuar con otras personas. En las granjas es prácticamente imposible hablar con ellos, pero cuando acuden a la villa de Saint-Rémi —en especial cuando van a hacer sus compras de alimentos- un chofer canadiense los transporta en autobuses escolares; de hecho, en los estacionamientos de los supermercados se pueden ver varios camiones los fines de semana. Se supone que es una "prestación" dado que las granjas se encuentran en los alrededores - a varios kilómetros de distancia- y es más fácil ir en un transporte motorizado que en bicicleta (de uso común entre ellos); pero en diversas ocasiones que me acerqué a abordar a los mexicanos, el chofer me cuestionaba, e incluso me impedía hablar con ellos. Algunos trabajadores me anotaban apresuradamente su número de teléfono celular en un papel para que yo me comunicara después, ante la insistencia del canadiense para que me retirara de ahí. Esta limitación en la movilidad de los trabajadores me fue señalada por una informante clave, inclusive, dijo, "les guardan sus documentos, como pasaporte y boleto de avión, como medida de seguridad, según, para que no se les pierda" (Berenice, defensora de los derechos de los trabajadores agrícolas temporales en la región de Saint-Rémi, Quebec).

Este "paternalismo" lleva implícita una medida de control sobre los trabajadores; la intención es que permanezcan en la granja, bajo supervisión, y que interactúen lo menos posible con personas de la sociedad civil quebequesa, probablemente para no facilitarles su estancia permanente en Canadá.

La comunicación es casi nula, pues los granjeros (patrones o capataces) hablan muy poco español, y los migrantes no tienen muchas oportunidades de estudiar francés. Los propietarios de las granjas hacen pequeños esfuerzos para integrar a los trabajadores temporales, como hacer una misa en español al año, e invitarlos al día nacional de Quebec, el 24 de junio. Como dice una informante del TUAC: "te queremos para que trabajes, pero no para que te adaptes... travaillez vite, vite, vite!" (Berenice, defensora de los derechos humanos de los trabajadores agrícolas temporales en la región de Saint Rémi, Quebec) (Figuras 4 y 5). 


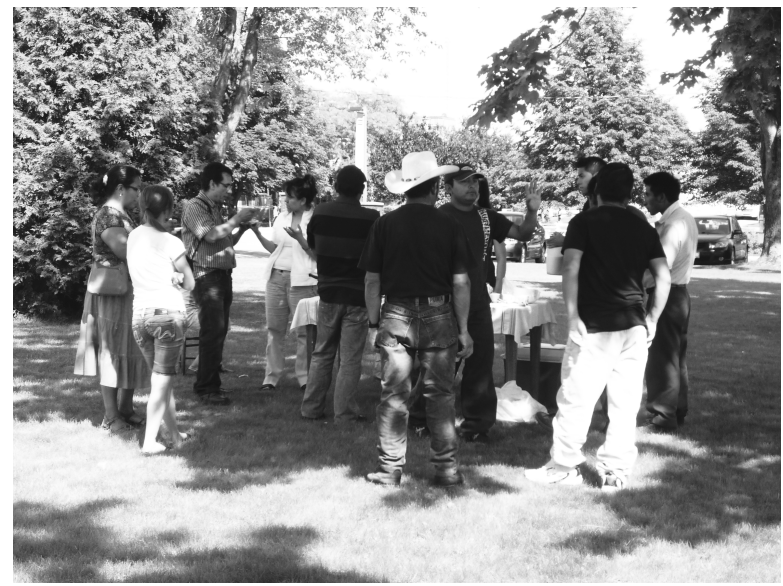

FiguRA 4. Trabajadores agrícolas temporales en una reunión con voluntarios de la Iglesia católica de Saint-Rémi. Fotografía de la autora.

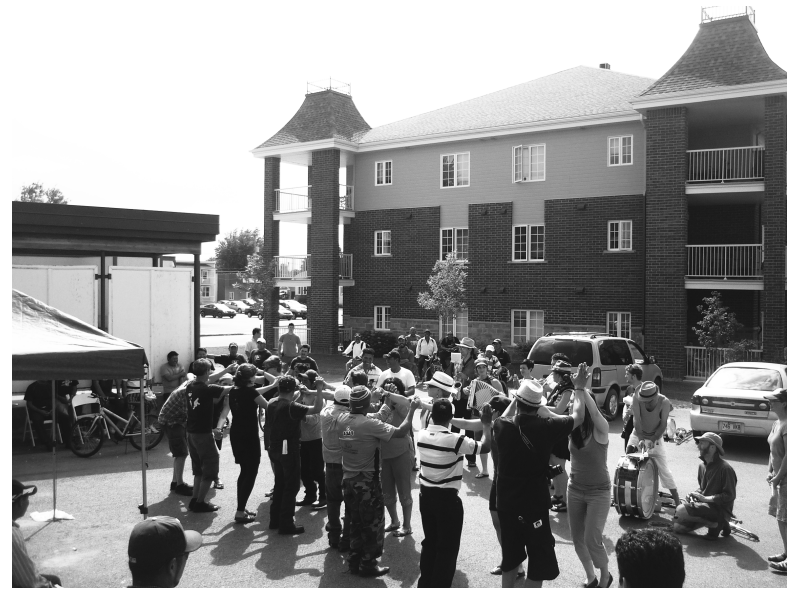

FIGURA 5. Comida y baile ofrecidos por representantes y voluntarios de la organización de defensa de los derechos de los trabajadores inmigrantes: Travailleurs et Travailleuses Unis de L'alimentation et du Commerce en Saint-Rémi, Quebec. Fotografía de la autora.

Las primeras veces que iba allá era muy aburrido, no conoces a nadie, no puedes ni hablar el idioma; he aprendido un poquito de francés, por ejemplo, los saludos, a preguntar cuánto cuesta, los números y así, pero poco (Jacinto, Maní, entrevistado en Yucatán).

Los quebecos hablan un poco español también, te dicen: buenos días, ¿cómo estás?, te tratan bien. En los primeros años cuando fuimos no; nomás: "no comprender, no parlar". Ahora entre nosotros más o menos un poquito, nos explicamos bien; hay más amistad ahora que antes (Tomás, Maní, entrevistado en Yucatán). 
Los patrones explican un poco el francés, pero clases no hay, hay una muchacha que es maestra, entonces los domingos nos enseña un poco de francés; pero algunos aprenden, pero la mayoría no aprendemos, no se nos queda (Felipe, Mama, entrevistado en Yucatán).

En cuanto al tema de la salud, los inmigrantes tienen derecho al servicio médico mediante la presentación de una tarjeta denominada assurance maladie, aunque en la mayoría de los casos el trabajador no la tiene en su poder; por lo que en caso de emergencias médicas durante días festivos o fines de semana, debe pagar por una consulta un mínimo de \$60.00 dólares. El TUAC (Travailleurs et Travailleuses Unis de L'alimentation et du Commerce) ha apoyado a mexicanos que se encontraban en peligro de muerte, entre ellos, uno que enfermó de apendicitis (convertida en peritonitis), y otro que quedó en coma a raíz de un accidente vial. En el último caso, de acuerdo con un informante clave anónimo, las autoridades del consulado mexicano habían consentido en "desconectar" al mexicano, lo que no permitieron los defensores de derechos humanos del TUAC. Finalmente, después de varios meses, el trabajador salió del coma, y en 2012 se hallaba en recuperación.

Por otro lado, los yucatecos refirieron otras violaciones a la dignidad de la persona y a su derecho a la salud. Cuando en 2009 se presentó la gripe AH1N1 varios mexicanos fueron aislados y maltratados. A quienes enfermaban de las vías respiratorias se les llegó a negar el servicio médico y las medicinas; además, obviamente, de no permitirles que laboraran en los campos agrícolas, los viveros o las empacadoras:

Con la AH1N1, nos tuvieron encerrados cuatro días, no nos querían sacar, ese problema se agrandó un poco porque los canadienses nos veían y se hacían a un lado, decíamos que éramos mexicanos y ahí sí nos discriminaban (...) No nos hicieron nada, (...) nosotros nos automedicamos porque no había de otra, había varios que decían "no tengo nada" pero sientes que tu cuerpo te duele y la nariz, no te puedes quedar así. Nos tuvieron cuatro días [aislados] porque tampoco querían tenernos más tiempo, porque al dar cinco días, ellos tenían [que] pagarnos los días inhábiles y no les convenía a ellos; cuatro no te pagan, pero al quinto día tienen que pagarte; son listos. Solamente a un muchacho que se enfermó y tenía una infección en los riñones, él duró 15 días sin trabajar, a ése si le pagaban normal 8 horas, se enfermó dos veces más y a la tercera le dijeron que tratara de no enfermarse porque salía caro llamar a las ambulancias (...) [pero] ya no los piden a ellos; revocan su contrato, ya no los quieren por enfermizos, como un motor, mientras trabajas bien no hay problema pero si te enfermaste ya, y ese muchacho sí era enfermo, a veces nos íbamos a las tres de la mañana al hospital, esperando a que salga, porque yo le ayudaba, yo le traducía un poco, y a las ocho entrar otra vez al trabajo (Basilio, Dzidzantún, entrevistado en Yucatán).

Un beneficio para los trabajadores - hasta 2012 - era el acceso a la prestación social por paternidad o maternidad denominada prestation parental o parental 
benefit, a través de la cual, quien hubiese laborado más de 600 horas en la temporada en la cual nacería uno de sus hijos, y cuyos ingresos semanales en México no superasen los \$75.00 dólares, podía obtener un porcentaje de su salario durante un período no mayor de 35 semanas. El trabajador debía integrar un expediente -en francés- y a su retorno a Quebec, anexar el documento oficial del beneficio de paternidad/maternidad a su declaración de impuestos. De no hacerlo así, el monto total del pago le sería descontado. Sin embargo, en el primer trimestre de 2013 esta prestación fue anulada:

Si una niña o un niño nace en tu hogar, antes de un año, puedes arreglar tus papeles y el gobierno te ayuda. Un año el gobierno te da como 7,000 dólares (Tomás, Maní, entrevistado en Yucatán).

Una ocasión pedí de paternidad y sí se me otorgó, sí estuvo bien. Aquí la pasa uno bien, y con el trabajo no se ve mucho el tiempo, por las horas de trabajo (Rodrigo, Tunkás, entrevistado en Quebec).

Ahorita me está llegando una ayuda de un hijo, que me aprobaron, me pagan mensual como 12,000 o 10,000, me mandan mensual en dinero mexicano. Un amigo de Maní me comentó que posiblemente hasta 50,000, la estancia en México por la niña. El gobierno de Canadá nos ayuda en ese aspecto, si vuelvo podría comprar otra casa o prosperar, no me iría a vivir [allá], sólo a trabajar... (Felipe, Mama, entrevistado en Yucatán).

Yo por ejemplo apliqué por mi hijo, el bebé que tiene mi esposa y se me dio un beneficio a mí; es lo que hago, llegando y aplicando para que el gobierno no me vaya a cobrar, hay cargos por no aplicar antes [se refiere a dar aviso en la siguiente temporada al gobierno de Quebec, de que gozó del derecho de paternidad]. [El monto] varía del tiempo que haces en Canadá; la niña que tengo la apliqué esa vez, pero como me tocó la misma temporada que no tardé acá, me dieron sólo 2,800 dólares, y de mi [otro] bebé me dieron como 8,500 dólares. Eso fue lo que hizo que me comprara el vehículo y me hice un cuarto grande allá atrás. Invertí en varias cosas nuevas (Basilio, Dzidzantún, entrevistado en Yucatán).

Como se puede observar las condiciones laborales de los participantes en el PTAT no son óptimas en términos del respeto a los derechos humanos. No obstante, hay que reconocer que los campesinos poseen mayor seguridad de transito al salir de México con un pasaporte y una visa de trabajo (por ser reconocido en un programa bilateral y estipularse el salario que recibirán), y finalmente porque, de una u otra forma, están casi seguros de que el año siguiente retornarán a Canadá, y después a sus lugares de origen con recursos económicos que les permitirán realizar algunos de sus sueños y proyectos, los cuales, de otra manera, serían imposibles. 


\section{Algunas reflexiones finales}

En este artículo se han mostrado algunos elementos que permiten sugerir que, a pesar de que el PTAT es un programa bilateral entre México y Canadá, y que las reglas para su operación son claras, existen violaciones a los derechos de los trabajadores. En el año en que realicé el trabajo de campo en Quebec (2012) diferentes trabajadores mexicanos - no sólo yucatecos - conversaban sobre la necesidad de constituir una agrupación sindical a través de la cual pudieran hacer valer tanto sus derechos laborales como los que competen al ámbito más general de los derechos humanos, como ser tratados con dignidad, no limitar su libertad de tránsito por la región, e inclusive por el resto de Canadá. O por ejemplo, la posibilidad de que si alguno así lo desea pueda ir acompañado por su esposa o pareja sentimental. Otra cuestión, que rebasa los límites y objetivos de este artículo, pero que vale la pena mencionar, es sobre el ejercicio de la ciudadanía de los migrantes internacionales.

$\mathrm{Si}$ - como sostiene la antropología — persistimos por el reconocimiento de los otros, entonces pensar en la ciudadanía —y su ejercicio- es central; sobre todo, en sociedades interculturales que suponen trascender la mera convivencia en un lugar para arribar a la interacción de las distintas culturas en un mismo espacio (Elósegui, 2010). Aunque pasar de la teoría a la práctica siempre ha resultado un lindero poco transitable, pues una cosa es lo que establece la definición de un concepto, como el de "interculturalidad", y otra, los retos que plantea la convivencia. Ya desde los años setenta, Quebec se demarcó de Canadá, al considerar que el multiculturalismo — promovido por el gobierno federal— generaba únicamente convivencia por medio de "fragmentos culturales", pues no lograba integrar a los francófonos (González Ulloa, 2014: 174). Esta aproximación de identidades limitadas o fragmentadas data de los años sesenta cuando las crecientes migraciones hicieron pensar que era "necesario renunciar a construir la nacionalidad sobre premisas de homogeneidad; algunos llegaron a afirmar que el hecho mismo de la diversidad era una (sic) componente esencial de la cultura nacional" (Boucahrd, 2003: 407). Los quebequenses optaron por la interculturalidad, centrada en la idea de integración a la cultura y la lengua oficial de Quebec, el francés; mientras que el multiculturalismo canadiense se concentró en reconocer la diversidad, identificando las diferencias. No obstante, ninguna de las dos aproximaciones ha resuelto la problemática de las desigualdades interétnicas, muy visibles en las poblaciones migrantes del llamado tercer mundo (ibid., 174). En su desenfrenada búsqueda de la identidad, la sociedad de Quebec ha tenido dificultades con el principio de accommodements raissonables y su operación.

Con la definición clásica de "ciudadanía" ocurre algo similar; en principio estamos habituados a pensarla como sinónimo de nacionalidad. Así, por antonomasia, la ciudadanía corresponde a los nacionales y no a los extranjeros, y en ese sentido, continúa anclada al territorio de nacimiento. En América hace falta traspasar muchos linderos antes de plantear, como en la Unión Europea ya se ha hecho, que todo ciudadano tiene derecho de sufragio activo en las elecciones 
municipales del Estado miembro en que resida, en las mismas condiciones que los nacionales de dicho Estado. Es decir, no es necesario haber nacido o tener la nacionalidad del país en que se vota; el único requisito es haber vivido ahí los últimos seis meses. Los migrantes temporales se encuentran lejos de compartir esos espacios de ciudadanía con los nacionales de Canadá. De momento hay que apuntar al pleno respeto de los derechos humanos (dignidad, salud, educación, libre tránsito, libertad de opinión), ya que los trabajadores agrícolas temporales en Quebec no son siquiera objeto de las discusiones y principios que plantean los accommodements raissonables. Finalmente, son solo fuerza de trabajo con un contrato jurídico. Y como señala Javier Lucas: "El verdadero y buen inmigrante es el trabajador extranjero extracomunitario que disciplinadamente viaja para cumplir una función y regresa a su lugar de origen sin dejar rastro, sin alterar la sociedad de destino y sin costes" (Lucas, 2006: 6).

\section{BIBLIOGRAFÍA}

Alejos García, José

1992 "Cultura y modernidad. La problemática de los mayas en las naciones independientes", Del katún al siglo. Tiempos de colonialismo y resistencia entre los mayas, pp. 163-190, María del Carmen León, Mario Humberto Ruz y José Alejos (eds.). México: Consejo Nacional para la Cultura y las Artes.

Becerril Quintana, Ofelia

1995 "Entre rosas y espinas los andares femeninos", tesis de Maestría en Antropología Social. México: Instituto Nacional de Antropología e Historia, Escuela Nacional de Antropología e Historia.

2011 iSoy un tunante, cual loco caminante!: transmigrantes mexicanos en Canadá contendiendo por el género, la sexualidad y la identidad. Michoacán: El Colegio de Michoacán.

Bouchard, Gérard

2003 "Otras trayectorias. Canadá, Nueva Zelanda y Estados Unidos”, Génesis de las naciones y culturas del Nuevo Mundo, pp. 393-463. México: Fondo de Cultura Económica.

Castellanos, Bianet

2012 "Tracing Indigeneity in Cancún: Maya Subjectivities, Urban Migration and Translocal Spaces", Cahiers Dialog. Indienous People in Urban Centers: Tracing Mobility in a Post Nafta World, pp. 3-7, Bianet Castellanos e Ivonne Vizcarra (eds.). Montreal: Aboriginal Peoples Research and Knowledge Network (DIALOG) e Institut National de la Recherche Scientifique (INRS).

Certau, Michel de

2000 "Relatos de espacio", La invención de lo cotidiano. I. Artes de hacer, pp. 127142, Alejandro Pescador (trad.) y Luce Giard (ed.). México: Instituto Tecnológico de Estudios Superiores de Occidente y Universidad Iberoamericana. 
Chourdy, Aziz, Jil Hanley, Steve Jordan, Eric Shragge y Martha Stiegma

2009 "Context", Figth Back, Workplace Justice for Immigrants, pp. 15-32. Montreal: Fernwood Publishing.

Commission des Normes du Travail

2014 "Les normes du travail au Québec", Commission des Normes du Travail, <http:// www.cnt.gouv.qc.ca/fileadmin/pdf/publications/c_0149.pdf> [Consultada el 7 de noviembre de 2014].

Conseil Interculturel de Montréal

2007 "Accommoder pour mieux vivre ensemble: pour une mise à jour du modèle québécois de intégration et de gestion de la diversité. Mémoire du Conseil Interculturel de Montréal présenté à la Commission de consultation sur les pratiques d'accommodements reliées aux différences culturelles". Montreal, Quebec: Ed. Conseil Interculturel de Montréal, <http://ville.montreal.qc.ca/ pls/portal/docs/page/conseil_interc_fr/media/documents/Memoire_Commission_Bouchard_Taylor.pdf $>$ [Consultada el 14 de agosto de 2014].

Elósegui Itxaso, María

2010 "El modelo de interculturalidad en el informe de la Comisión BouchardTaylor para Quebec", Anuario de Derechos Humanos, Nueva Época, 11: 129-164, $<$ http://issuu.com/irelaaleman/docs/modelo-bouchard-taylor > [Consultada el 9 de mayo de 2012].

Gámez Gastélum, Rosalinda

2009 "Evaluación del programa de trabajadores agrícolas temporales MéxicoCanadá. Caso Sinaloa”, Observatorio de la Economía Latinoamericana, 112, $<$ http://www.eumed.net/cursecon/ecolat/mx/2009/rgg.htm > [Consultada el 20 de mayo de 2013].

González Ulloa, Pablo

2014 "El multiculturalismo en Canadá: la redefinición de las políticas de la inclusión y sus teóricos”, Revista Norteamérica, 9 (1): 171-206.

Gouvernement du Canada

2012 "Profil du recensement Saint-Rémi, Quebec", Statistics Canada, < http://www12. statcan.gc.ca/census-recensement/2011/dp-pd/prof/index.cfm?Lang=E > [Consultada el 24 de octubre de 2012].

López Morales, Laura

2000 "Entre tradición y ruptura: la cultura quebequense", Canadá un estado posmoderno, pp. 527-536, Teresa Gutiérrez-Haces (coord.). México: Plaza y Valdés.

Lucas, Javier

2006 "La ciudadanía para los inmigrantes: una condición de la Europa democrática y multicultural”, Revista de Filosofía, 4: 1-19. 
Preibisch, Kerry

2015 "Los trabajadores migrantes y los cambios en los regímenes laborales en la producción agrícola contemporánea de Canadá”, Hacia el otro norte. Mexicanos en Canadá, pp. 115-139, Sara María Lara Flores, Jorge Pantaleón y Martha Judith Sánchez Gómez (coords.). Buenos Aires: Consejo Latinoamericano de Ciencias Sociales (CLACSO).

Radio Canada

2013 "Ottawa annonce une reforme du programme des travailleurs étrangers", $<$ http://www.radio-canada.ca/nouvelles/Economie/2013/04/003-changementsprogramme-travailleurs-etrangers-canada.shtml > [Consultada: 29 de abril de 2013].

Re Cruz, Alicia

2005 "Turismo y migración entre los mayas de Yucatán. Las nuevas milpas de Chan Kom”, Revista Española de Antropología Americana, 36: 149-162.

2009 "When Immigrants Root and Transnational Communities Grow", Urban Anthropology and Studies of Cultural Systems and World Economic Development, 38 (2-4): 12-148.

Rosales, Adriana Leona

2010 "Contextos genéricos y sexuales en grupos étnicos minoritarios contemporáneos”, Sexualidades, cuerpo y género en culturas indígenas y rurales, pp. 153-203. Mexico: Universidad Pedagógica Nacional.

Secretaría de Relaciones Exteriores

s.f. $\quad$ "Programa de Trabajadores Agrícolas Temporales México-Canadá", Consulado General de México en Toronto, <http://consulmex.sre.gob.mx/toronto/index. php/es/programa-de-trabajadores-agricolas $>$ [Consultada el 11 de mayo de 2013].

Service du Capital Humaine et des Communications, Direction du Greffe à la Direction Générale

2012 La Charte Montréalaise des Droits et des Responsabilités, < http://ville.montreal. qc.ca/pls/portal/docs/PAGE/CHARTE MTL FR/MEDIA/DOCUMENTS/CHARTE MONTREALAISE_DES_DROITS_ET_RESPONSABILITES.pdf $>$ [Consultada el $\overline{9}$ de mayo de 2013].

Verduzco, Gustavo

2004 The Temporary Mexican Migrant Labor Program in Canadian Agriculture. San Diego: University of California, The Center for Comparative Immigration Studies (CCIS).

2007a The impact of Canadian Labour Experience on the Households of Mexicans. Ottawa: Canadian Foundation for de Americas (FOCAL).

2007b "Lecciones del Programa de Trabajadores Temporales Mexicanos en la agricultura de Canadá. Una buena práctica amenazada”, Trabajo temporal y migración internacional a partir de la experiencia México-Canadá, pp. 11-46. México: El Colegio de la Frontera Norte y Miguel Ángel Porrúa Editor. 
2008 "Enseñanzas del Programa de Trabajadores Agrícolas Temporales de México en Canadá: una oportunidad en riesgo", La gestión de la migración MéxicoEstados Unidos: Un enfoque binacional, pp. 307-334, Agustín Escobar y Susan F. Martin (coords.). México: Centro de Investigacions y Estudios Superiores en Antropología Social-Occidente, Secretaría de Gobernación, Instituto Nacional de Migración y DGE Equilibristas, S.A. de C.V. 